\title{
"The place where I live is where I belong": community perspectives on climate change and climate-related migration in the Pacific island nation of Vanuatu
}

\author{
Nikita Perumal \\ Columbia University Human Rights Department, USA \\ nsp2122@columbia.edu
}

\begin{abstract}
In recent years, narratives of the 'climate refugee' have abounded within the larger conversation regarding climate change. However, anthropologies from climatevulnerable Pacific Islands - particularly those most targeted by 'climate refugee' discoursehave determined that the way many media outlets and policy specialists speak of climaterelated migration is sensationalized, over-simplistic, and unrepresentative of how Pacific Islanders approach the issue. Aimed at illustrating how local context can add necessary nuance to the 'climate refugee' narrative, this paper investigates community perspectives on climaterelated migration within a Pacific Island that has not yet been covered in the literature- the Melanesian country of Vanuatu. Based on qualitative fieldwork in Port Vila, Vanuatu, I explore the positions of ni-Vanuatu policymakers and climate activists regarding migration linked to climate change and argue that these be incorporated into policy analyses of climaterelated migration in the Pacific. I find that ni-Vanuatu perspectives reflect an unwillingness to resettle as a result of climate change unless as a last resort, a prioritization of in-situ adaptation measures, and a preoccupation with maintaining cultural and livelihood links should resettlement occur. The implication of these findings is that policies that center these perspectives would allow for community control over movement - including the decision of whether to relocate at all. It will also emphasize prevention and minimization of the circumstances that precipitate climate-related migration. These findings serve as an original contribution to the topic of climate-related migration in Vanuatu-on which no scholarship has been done previously — and as representative of similar island nations.
\end{abstract}

Keywords: climate change, climate refugees, climate-related migration, community perspectives, migration, Pacific Islands, Vanuatu

https://doi.org/10.24043/isj.50

(C) 2018 - Institute of Island Studies, University of Prince Edward Island, Canada.

\section{Introduction}

Small island developing states (SIDS) have become the poster children for the phenomenon of climate-related migration, through which the impacts of climate change-increasingly intense weather events and natural disasters, drought, ocean acidification, and a projected rise in sea level of at least one meter (Gerrard \& Wannier, 2013, p. 8)-render certain homes, countries, and areas uninhabitable. A commonly cited (yet often disputed) statistic approximates the emergence of roughly 200 million climate change refugees by 2050 (Gerrard \& Wannier, 2013, p. 5). Indeed, major news outlets consistently publish media pieces on the plight of Pacific Islanders and the prospect they face of leaving their country as it crumbles into the sea (McNamara \& Gibson, 2009, p. 479). The narrative of the 'climate change refugee' - a person forced across borders from their homeland as a result of climate change 


\section{Nikita Perumal}

impacts (McNamara \& Gibson, 2009, p. 475) - is thus a visible part of climate change discourse. The validity of this 'climate refugee' label, and associated debate about policies and mechanisms to protect those who move because of climate impacts, has also been the subject of countless policy and legal analyses (Ash \& Campbell, 2016; Biermann \& Boas, 2008; Byrayan \& Rajan, 2006; Hodgkinson \& Young, 2013; Soloman \& Warner, 2013; Williams, 2008; Wyett, 2014). However, this narrative has attracted criticism, particularly from scholars who have conducted fieldwork in the vulnerable areas in question, for being both sensationalized and over-simplistic (Farbotko \& Lazrus, 2012; McAdam, 2012; McNamara \& Gibson, 2009). Anthropologies of specific Pacific Island communities-particularly atoll nations most targeted by 'climate refugee' dialogue - have found that the way both the media and many policy specialists speak of climate-related migration is far more one-dimensional than how islanders approach the issue.

The disjuncture between policy analyses and anthropologies of affected local communities regarding climate migration begs the question: How can community perspectives inform analysis and policy formulation around the question of climate changerelated migration? Answering this question is made complicated by the fact that "there is a paucity of empirical work on local people's perspectives of climate change impacts and the role of migration as a potential adaptation strategy" in the Pacific (Allgood \& McNamara, 2017, p. 372). Of these empirical works, there is an overwhelming focus on Tuvalu, Kiribati, and the Marshall Islands (Allgood \& McNamara, 2017; Constable, 2016; Farbotko \& Lazrus, 2012; McNamara \& Gibson, 2009; Mortreux \& Barnett, 2009). Some literature also exists on specific communities in Fiji (McNamara \& Des Combes, 2015), the Solomon Islands (Monson \& Foukona, 2014), and Papua New Guinea (Donner, 2015; Rakova et al., 2009).

This study seeks both to answer the question of how community perspectives can inform climate migration policy, and to fill in gaps surrounding empirical research on these community perspectives, in a Pacific Island that has not yet been addressed in the literaturethe Melanesian country of Vanuatu. Based on qualitative fieldwork in Port Vila, Vanuatu, I argue that incorporating the wishes of affected communities into policy responses offers the possibility of more nuanced, effective, and responsible approaches to the complexities of climate-related migration. Islander perspectives in Vanuatu reveal a reluctance to resettle as a result of climate change unless as a last resort, a prioritization of in-situ adaptation measures, and a preoccupation with maintaining cultural and livelihood links should resettlement ever occur. With this in mind, community-based policy, which inherently centers the perspectives, participation, and decision-making of affected communities, would allow for community member control over movement - including the decision of whether to move at all. It would also emphasize prevention and minimization of the circumstances that precipitate climate-related migration. Community-informed approaches to policy on climate migration may serve to bridge the inconsistencies between the place-specific findings of environmental anthropologists and the broader generalizations of many policy experts who work on the issue. This is particularly important given that "much literature surrounding climate change impacts in the Pacific and appropriate policy response fails to engage with policymakers, spokespeople and 'laypeople' within the Pacific regarding the geopolitics of relocation and migration" (Constable, 2016, p. 1035).

To substantiate this claim, I separate my argument into two sections. The first section contrasts the prevailing - and ultimately reductive-debates that preoccupy many policy analyses about Pacific climate migration with a number of anthropologies from specific Pacific Islands, thus illustrating the shortcomings of these analyses and the need for local context in addressing the climate migration paradigm. The second section presents the findings of my fieldwork within the context of Vanuatu, collected through a series of semi-structured interviews, and advocates for community perspectives as crucial to the formation of effective, locally appropriate policy around climate-related migration. 
Given that there is a tendency to conflate and misuse terms in this realm of scholarship (Constable, 2016), it is important to clarify my use of terminology. There is no established distinction between forced migration (often referred to as 'displacement') and voluntary migration (Ash \& Campbell, 2016), and it is well acknowledged in the literature that individual, household, or community decisions to voluntarily migrate can never be attributed entirely to climate change (Campbell, 2012; McAdam, 2012; Mortreux \& Barnett, 2009; Nurse et al., 2014). Rather, a decision to voluntarily migrate is the culmination of a host of intertwining considerations - such as socioeconomic push and pull factors, personal considerations, and barriers like distance or institutional constraints - that may include, and may be exacerbated by, climate change (Constable, 2016; McAdam, 2012; Mortreux \& Barnett, 2009; Nurse et al., 2014). Out of the many subsets of climate migration, the implication of the term in this paper is of long-term, voluntary, community-level resettlement. Throughout the paper, I refer to this phenomenon as 'climate-related migration' or simply 'climate migration'.

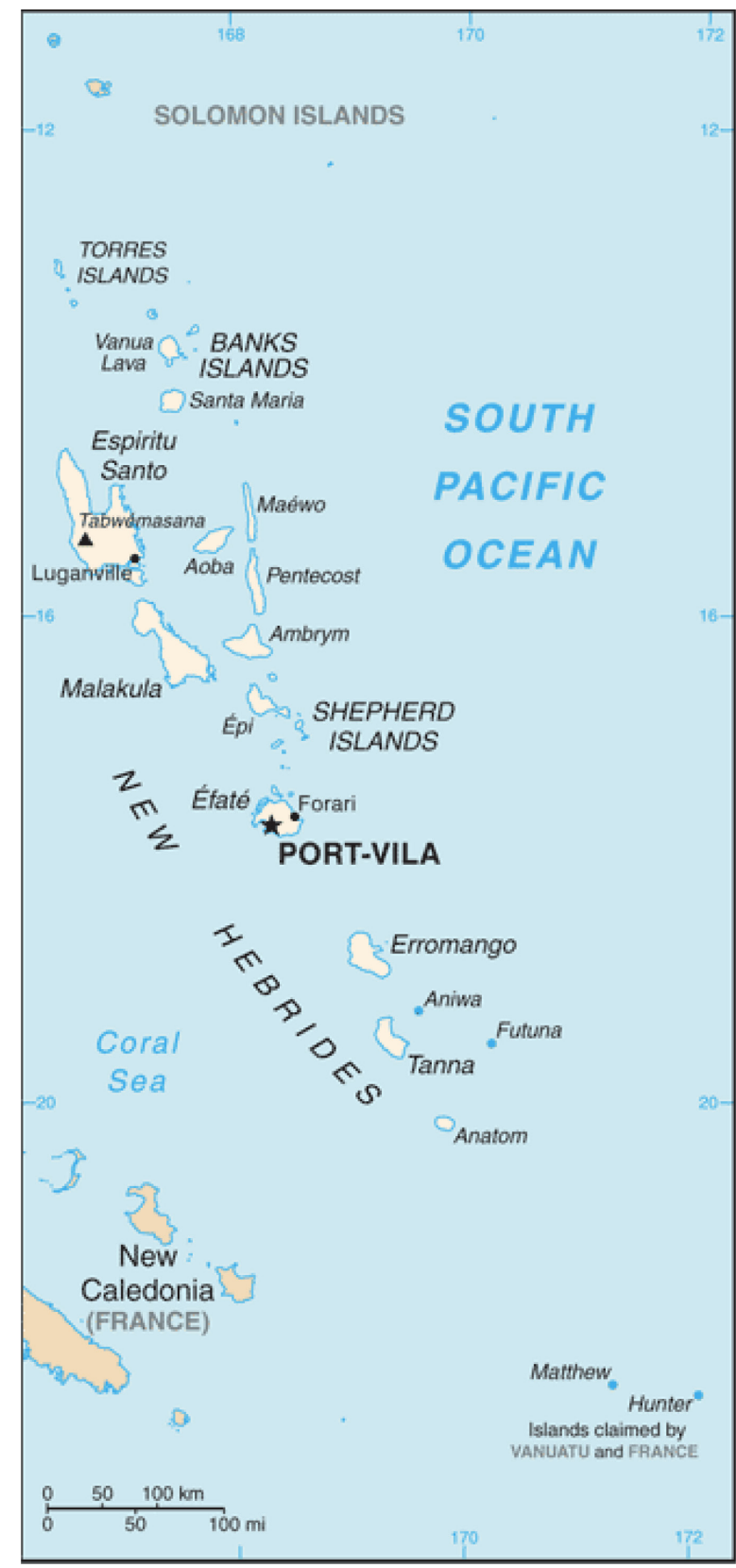

Figure 1: Map of Vanuatu. Source: Central Intelligence Agency, https://www.cia.gov/library/publications/the-world-factbook/geos/nh.html. 


\section{Vanuatu: a case study}

The basis of my argument is evidence collected from a case study performed in the capital of Vanuatu—a 12,190 $\mathrm{km}^{2}$ archipelago (Petz, 2013, p. 54) of 83 primarily volcanic islands in the South Pacific that is highly vulnerable to climate change impacts (Vachette, 2016; UNDP, 2014). Vanuatu belongs to the Melanesian sub-region of Oceania and is divided into six provinces-Malampa, Penama, Sanma, Shefa, Tafea, and Torba-that comprise different groups of islands. Over three-fourths of ni-Vanuatu people depend on subsistence agriculture and fisheries, marine resources, and remittances (Webb et al., 2015, p. 408), while most of the formal economy takes place in the country's urbanized capital, Port Vila (Craven, 2015, p. 224). Vanuatu is one of the most linguistically diverse countries in the world: Its population of 270,402 (World Bank, 2017) speaks well over 100 local languages (CIA, 2014, p. 5). The country's islands reflect a varied topography of elevated, forested land and some coastal plains (CIA, 2014, p. 5).

While several scholars have examined community perceptions of climate-related migration in the most heavily mediatized Pacific island nations (Farbotko \& Lazrus, 2012; McAdam \& Loughry, 2012; McNamara \& Gibson, 2009), none have examined this question within the context of Vanuatu. Vanuatu is not as low-lying as the handful of coral atoll nations that are most often positioned as players in the 'climate refugee crisis' (e.g. Tuvalu, Kiribati, the Marshall Islands), and sea level rise is not the primary climate change impact that threatens the country (McNamara \& Gibson, 2009, p. 476).

In terms of natural disasters, however, the World Risk Report considers Vanuatu more at risk and more exposed than any country in the world (Comes et al., 2016). Vanuatu has exposure to cyclones, flooding, storm surge, landslides, prolonged drought and wet periods driven by the El Niño Southern Oscillation, frequent earthquakes, and occasional tsunamis and volcanic eruptions (Petz, 2013, p. 16). Climate change is expected to increase the intensity of both droughts and extreme weather events like storms and cyclones (Hugo \& Bedford, 2012; Campbell \& Warrick, 2014; Petz, 2013). These impacts-alongside ocean acidification, and saltwater intrusion (Webb et. al, 2015) - will have a more direct impact on the ni-Vanuatu people than will sea level rise. For example, Webb et al. (2015, p. 408) have already observed disruptions of crop production and food security in Vanuatu as a result of climate variability. Furthermore, some of Vanuatu's more low-lying coastal areas, including parts of its urban center Port Vila, will be relatively more susceptible to sea level rise and coastal erosion than other parts of the country (Campbell \& Warrick, 2014; Petz, 2013).

This reality renders any environmental change that Vanuatu may experience more complex than the traditional 'climate refugee' narrative allows for. Vanuatu, as a 'high island', does not face immediate questions about cross-border climate migration prompted by sea level rise; rather, the country grapples with predominantly far-off (but not necessarily inevitable) possibilities of migration and with the associated impacts such migration will have on communities' cultures, livelihoods, and climate adaptation strategies.

Vanuatu's status as a 'high island' is also interesting because, despite its distinction from atoll nations that more intimately face potential sea level rise, the country is still often characterized by journalists and policy analysts as at high risk for climate migration simply because it is a Pacific Island (McNamara \& Gibson, 2009, p. 478). For example, a relatively recent article in The Guardian evaluates the access that some Pacific Islands have to migration pathways before lamenting, "but the people of PNG, the Solomon Islands, Vanuatu, Nauru and Kiribati have no such rights, and essentially no place to go" (Doherty, 2015). The article thus erroneously implies that these nations, Vanuatu included, will inevitably undergo levels of environmental change substantial enough to push their populations overseas. Similarly, in 2005, Tegua islanders' move within Vanuatu's northern Torres Islands-an instance of present-day relocation in Vanuatu-was heralded by media and the United Nations 
Environmental Programme as evidence of some of the first 'climate refugees'; in actuality, however, the village's choice to relocate was linked to a non-climatic geological process (Siméoni \& Ballu, 2012).

Academic scholarship also at times puts "forward the case that migration may be inevitable for many small island developing states," including Vanuatu (Allgood \& McNamara, 2017, p. 373). Several studies analyze the notion of climate migration throughout most Pacific Islands, not just atolls (Bedford \& Campbell, 2013; Campbell \& Warrick, 2014; Petz, 2013; Wyett, 2014). Campbell \& Warrick (2014, p. 19), for instance, argue: "climate change may induce and force migration from a large number of Pacific island countries [...] it is essential not to neglect [non-atolls] that may be just as exposed but in different ways." Other scholars echo this reasoning by including Vanuatu in their respective calls for climate migration-related 'policy intervention' in specific island nations (Ash \& Campbell, 2016; Wyett, 2014). Wyett (2014, p. 182) even discusses possible "host countries," implying that migration from states she identifies will likely be cross-border.

The fact that climate-related mobility within Vanuatu has already been subject to media scrutiny and scholarly discussions affirms the island nation's attractiveness as a case study for the research question. If climate migration policy is to be formulated-and is indeed already being discussed-within the context of Vanuatu, understanding ni-Vanuatu perspectives on climate migration as a strategy is crucial. At the same time, however, it is important to constrain the majority of this argument to Vanuatu and similar island nations of which the case study may be representative.

\section{Methodology}

The qualitative fieldwork underpinning this paper was conducted in January 2016 as a series of hour-long, semi-structured interviews with 19 policymakers, scholars, and civil society members in Vanuatu's capital Port Vila, on the island of Efate. The analytical method used an emergent, rather than pre-set, coding method to identify trends. For the sake of maintaining these participants' anonymity, I refer to them in this paper by neutral signifiers (e.g. Interviewee 1).

The eight policymakers I interviewed worked in or with Vanuatu's Ministry of Climate Change, and a majority were members of the recently-created National Advisory Board for Climate Change and Disaster Risk Reduction (NAB) - a committee of governmental and non-governmental members acting "as Vanuatu's supreme policy making and advisory body" for disaster risk reduction and climate change initiatives (NAB, 2016). The nine civil society members I spoke to worked for organizations that implement climate change adaptation projects in Vanuatu. Two of these organizations were international or regional organizations - the International Organization for Migration (IOM) and the German development organization GIZ-while the rest were locally-based NGOs. Lastly, I spoke with two local stakeholders who had scholarly expertise on ni-Vanuatu culture and legal systems. Fifteen of the 19 interviewees were ni-Vanuatu; five were women, and 14 were men.

Because the majority of my interviewees occupied relatively elite administrative positions in the country's capital, it is important to note that the perspectives I collected are by no means exhaustive or wholly inclusive of every subset of ni-Vanuatu society. Certain biases will inevitably arise from sourcing interviewees from NGO workers and policymakers in Port Vila. The capital is arguably more influenced by 'western' culture than the rest of the country, and interviewees' attitudes towards and ways of speaking about climate change will likely be different from those of villagers removed from urban areas (Granderson, 2017). This being said, 15 of 19 interviewees were themselves ni-Vanuatu, with familial and kinship ties with Vanuatu's outer islands; they all constituted, by Kelman's (2010, p. 606) standards, "local voices." Furthermore, because these actors work closely on climate policy and programs- 


\section{Nikita Perumal}

often working to implement adaptation projects at the community level-I consider them to have a substantial enough grasp of the mindsets of ni-Vanuatu communities regarding climate impacts to provide value to my findings. This reasoning does not, however, exclude the pressing need in subsequent studies for local perspectives from communities in Vanuatu's islands outside of Efate.

Another important qualification on methodology is the possibility of confirmation bias from respondents: It is possible that some tailored their responses to what they believed I wished to hear. Given this, I was careful to eliminate any sense of direction or expectation when phrasing and posing the questions.

\section{Beyond the 'climate refugee debate': the need for local perspectives}

\section{Limitations of mainstream climate migration policy analyses}

In an exhaustive document analysis, McNamara and Gibson (2009, p. 479) found that between 1970 and 2004, over 300 news articles about 'climate refugees' appeared in various media outlets, using language that was, "on the whole, dramatic and sensational." As discussed above, even Vanuatu - a 'high island' less exposed to sea level rise and the perceived existential threats associated with it - has been subject to this discourse, simply because it is a Pacific Island. However, a number of anthropologies have found that many Pacific Islanders find the label of 'climate refugee' offensive and incompatible with their own conceptions of "human dignity" (McAdam, 2012, p. 9) and agency in the face of climate change (Constable, 2016; Farbotko \& Lazrus, 2012; McNamara \& Gibson, 2009; Mortreux \& Barnett, 2009).

In this paper, my primary interest in the 'climate refugee' narrative is the way in which it has seeped into policy papers and academic studies, and why this in turn reinforces the need to add the context of local perspectives to policy recommendations on climate migration. It is important not to conflate media discourses of the 'climate change refugee' with policy analysis, but it is also vital to consider the impact that this media discourse can have on scholarly work. While the narrative of victimized, drowning islanders has been much more pervasive in the media than in literature by NGOs and academics (Constable, 2016; Mortreux \& Barnett, 2009), Farbotko and Lazrus (2012, p. 10) still observe that "the term climate refugee $[. .$.$] is becoming the basis for policy development." Indeed, even amongst academics$ and "experts in the field" (McAdam, 2012, p. 122), a number of papers draw upon imprecise language that evokes the 'climate refugee' concept (Barnett, 2017; McAdam, 2012). Early scholarship on this issue in particular tended to downplay island resilience, the complexity of migration, and capacity to adapt in-situ (Constable, 2016; Nurse et al., 2014; O'Neill \& Barnett, 2008).

Meanwhile, in the realm of policy scholarship, a number of political scientists and legal scholars debate 'the legal challenge' of climate-related migration: the fact that international and refugee law lack concrete protection mechanisms for those who would wish to relocate as a result of climate change, particularly across borders. Arguments abound for and against expanding the 1951 Refugee Convention to include protection for climate migrants, as well as for and against the creation of a new legal instrument specifically for their protection (among others, see Biermann \& Boas, 2008; Docherty \& Giannini, 2009; Falstrom, 2001; Hodgkinson \& Young, 2013; McAdam, 2012; Soloman \& Warner, 2013; Williams, 2008). Some have even gone beyond the realm of policy recommendations: The Australian Labour Party's "short-lived 2006 policy document, Our Drowning Neighbours" (Constable, 2016, p. 1033) and a 2007 legislative bill by the Australian Green Party both make concrete policy proposals for a 'climate refugee' visa status (Farbotko \& Lazrus, 2012, p. 10).

The significance to this paper of these scholarly debates, and of the few accompanying policy proposals, is their presumption about the likelihood of climate impacts precipitating migration, and about Pacific Islanders' willingness to move. It is given that "any discussion of 
developing migration pathways needs to respect that many people are not willing to leave their homes" (Constable, 2016, p. 1034)—yet very few of the policy pieces discussed above engage substantially with this fact, or allude to it. This is worrying to some Pacific scholars who fear that focusing on migration as a solution to climate-related challenges will in turn obfuscate and distract from other policy responses, such as in-situ adaptation and meaningful cuts in carbon emissions (Allgood \& McNamara, 2017; Barnett, 2017; Barnett \& O'Neill, 2012; Mortreux \& Barnett, 2009). Others go further, warning that a victimizing 'climate refugee' discourse "may directly undermine local adaptive capacity, if it reduces incentives for investors and donors to provide funding [...] and for islanders themselves to manage their resources sustainably" (Betzold, 2015, p. 483).

With this in mind, policy approaches that presume a high likelihood for climate migration across the Pacific, and that postulate in detail over legal protection mechanisms for these migrants, often seem at odds with literature capturing the realities and lived experiences of Pacific Islanders. For one, there is often a presumption-particularly for those who advocate 'refugee' terminology - that the potential migration in question will be cross-border. However, excluding small coral atoll countries, Pacific scholars agree that the majority of displacement in vulnerable islands will likely be within borders (Bedford \& Campbell, 2013; McAdam, 2012; Solomon \& Warner, 2013; Zetter, 2010). Second, many of these pieces are so strictly engaged with discussions of policy, law, and international relations that they miss a crucial reality described in many Pacific anthropologies: Not all Pacific Islanders will want to move to avoid climate impacts (Barnett \& O’Neill, 2012; McNamara \& Gibson, 2009; Mortreux \& Barnett, 2009), and islanders in both atoll and non-atoll countries who do migrate are primarily doing so as a result of drivers unrelated to climate change (Campbell, 2012; Mortreux \& Barnett, 2009; Nurse et al., 2014). Given many Pacific Islanders' reluctance to move, policy speculation about climate migration may sometimes lack the local context to ask the right questions and may obscure proposals for other adaptation options. Farbotko and Lazrus (2012, p. 16), for instance, observe a community preference for policies that would negate the need for migration or for protection as a refugee:

In the eyes of Tuvaluans, permission to cross a western border [...] falls far short of the climate change remedies required: extensive, immediate reductions in global greenhouse gas emissions, and significant legal and financial action to redress lost livelihoods and self-determination if emissions reduction is not achieved.

To these islanders, policy around climate-related migration requires so much more than the simple guarantee of migration pathways and rights. And yet, with the exception of Soloman and Warner (2013), none of the legal and policy papers reviewed above include any form of nuance about preventing the circumstances that would prompt migration. It follows that additional context is needed to widen the perspectives of these papers, and to foster that needed nuance.

The case for community perspectives in climate migration policy

A tangible disconnect exists between the anthropologies and policy pieces enumerated above. In a background paper by Australia's Human Rights and Equal Opportunity Commission (HREOC) (2008, p. 23) on Human Rights and Climate Change, for example, the authors commend a "proposal to resettle populations displaced by climate change in Australia" and argue that migration pathways like New Zealand's Pacific Access visa category ought to expand their eligibility requirements. By assuming that the only obstacles to resettling climateaffected populations are the eligibility terms of the Pacific Access visa category-and not the cultural and economic risks that might deter Pacific Islanders from moving to another country (Campbell, 2012, p. 78) — the background paper misses a key point. 


\section{Nikita Perumal}

The interviews I conducted in Vanuatu, like the Pacific anthropologies outlined above, revealed a strong aversion to the prospect of moving across borders to escape climate change impacts. All 19 interviewees agreed that, if relocation due to climate impacts were to occur at all, internal migration would be both preferable and more likely "because you can maintain your culture, your way of life" (Interviewee 12).

Similarly, the expansion of the refugee definition to climate-vulnerable populations is not in line with the expressed wishes of those who live in Vanuatu-despite the exhaustive discussion that has abounded in mainstream policy approaches regarding such an expansion. The activists and policymakers I interviewed in Port Vila indicated that they refused to accept the status of a 'climate refugee'. "We're almost admitting some sort of defeat when we talk about relocation," one NGO worker mentioned (Interviewee 1). A ni-Vanuatu climate activist reflected that "I think it's really confusing to talk about moving people from where they live to another place due to climate change [...] From my understanding, if you ask people to move from their own land, it's really difficult" (Interviewee 2). Such reflections echo back to the findings of Pacific Island-based scholarship, which illustrates a long-standing attachment to land in the Pacific and the complexity inherent in relocating from it (Allgood \& McNamara, 2016; Bonnemaison 1985; Campbell, 2012; Barnett \& O’Neill, 2012; Barnett \& Webber, 2012; McNamara \& Des Combes, 2015; Monson \& Foukona, 2014; Rakova et. al, 2009; Tonkinson 1985). While it is important not to discount the strong tradition of mobility in the Pacific (Barnett \& Campbell, 2015; Betzold, 2015; Lazrus, 2012; Warrick, 2011), it is also important not to discount the "extremely important losses that dislocation from the land will bring about" (Campbell, 2012, p. 78) for Pacific communities, and their reluctance to undergo that dislocation unless as a last resort.

Policy recommendations like the HREOC's, which are preoccupied with technical considerations like international visa categories, thus seem remarkably unaware of the local realities and nuances that are encapsulated in the above data. This is not to say that policy should not work to secure climate migrants' rights or to envision how the current "migration pathways deficit" (Constable, 2016, p. 1033) might be filled should internal or cross-border climate-related migration occur. But in not considering local context, such as a strong reluctance to migrate abroad, the paper renders itself almost irrelevant. At the same time, it contributes to a political atmosphere that may push cross-border migration over other adaptation or mitigation strategies as an appropriate response to climate change.

The example of the HREOC paper illustrates a salient point: policy that is not informed by the perceptions and viewpoints of the affected island communities will inevitably result in disconnect (Barnett, 2017; Barnett \& Campbell, 2015; Scott 1998). It also reinforces whyas scholars like Campbell and Warrick (2014), Ash and Campbell (2016), and Wyett (2014) make their cases for expanding and increasing policy development around climate change and migration in non-atoll islands such as Vanuatu-it is important to ensure that climate migration policy development incorporates a foundational understanding of ni-Vanuatu attitudes in its analysis. Indeed, if implemented, uninformed climate migration policy recommendations seem outright alarming, given that "resettlement schemes always fail when the people who are moved do not want to be, and/or have no control over the choice of destination and process of movement" (Barnett \& O'Neill, 2012, p. 10).

Community-informed policy will inherently center the perspectives and decisionmaking of affected communities. I posit that the policy that would emerge from this sort of community-based approach would be stronger as a result and would aid in avoiding the very real possibilities of maladaptation that can accompany climate-related resettlement (Barnett \& O'Neill, 2012). In the words of a policymaker who works in the office of Vanuatu's Shefa province, "community participation at all aspects [of policy] is a must [...] It makes for better policy when you give a voice to communities" (Interviewee 6). Reimagining how we want 
policy discussions around climate-related migration to better accommodate these voices, within the context of Vanuatu, is the subject of the next section.

\section{Notes from the field: recommendations for a community-informed approach to climate migration in Vanuatu}

A predominant reason that non-community based policy is so often misguided is its failure to take into account cultural considerations, such as how ni-Vanuatu identity is tied up in land. According to Campbell (2012, p. 60), "land in Pacific Island countries tends to have meanings to those who 'belong' to or are 'part of it' that are often difficult to encapsulate in English or other colonial languages." Policymakers, National Advisory Board (NAB) members, and civil society organizations alike expressed similar sentiments, noting: "culture is a mainstay of Vanuatu-if you take that away from [the people], it makes them more vulnerable" (Interviewee 3). One policymaker, whose extended family had relocated after a volcanic eruption, noted, "Vanuatu is a cultural place, [but] in some islands, there are cultures that are linked to the land. If [people] move away, they lose that culture and their resources" (Interviewee 4). These perspectives align well with the reflections of islanders in climate migration studies in other Pacific Islands (Campbell, 2012; Constable, 2016; Farbotko \& Lazrus, 2012; Mortreux \& Barnett 2009). Given the notions of "distinct identity, a feeling of belonging (because of genealogy and community), lifestyle, family connections, and culture, all of which seemed to be irrevocably tied to place" (Mortreux \& Barnett 2009, p. 110), it makes sense that choosing to migrate in response to climate impacts is not a decision that interviewees would make lightly.

Fourteen of the 15 ni-Vanuatu interviewees thus emphasized how cultures and livelihoods would be drastically, and worryingly, affected by climate-related relocation (Interviewees 2, 3, 4, 5, 6, 8, 9, 10, 11, 12, 13, 15, 16, 17). It should be noted here that cultural losses linked to migration may not be an entirely new phenomenon for these interviewees to consider; similar experiences are likely already occurring when ni-Vanuatu move from outer islands to Vila. However, the potential for migration-linked cultural loss in other contexts did not preclude interviewees' concern for this process within the context of climate-related migration.

This is also not to say that Pacific Islanders are fixed to their land to the point of inadaptability; many respondents commented on the larger migratory tradition that characterizes ni-Vanuatu society. Indeed, "the rootedness of Melanesian societies does not necessarily restrict the mobility of their membership" (Bonnemaison 1985, p. 48). Bonnemaison's (1985) seminal work on ni-Vanuatu mobility conjures the metaphor of "the tree and the canoe," which both links ni-Vanuatu to their land and enables them to "migrate with the knowledge that they always will have a home to which to return" (Campbell \& Warrick, 2014, p. 21). With this in mind, Barnett and Campbell $(2015$, p. 170) observe that "Pacific Island people have successfully coped with [various changes] for centuries, and sometimes migration is one among their many deliberate adjustment strategies." In Vanuatu, internal, mobility is common (Bonnemaison, 1985; Warrick, 2011, p. 218): Circular mobility in particular (Bedford, 1973; Bonnemaison, 1985) has been notable in past decades (Petrou, 2017). Resettlement has also taken place as a result of non-climatic processes, such as volcanic eruptions on the island of Ambrym (Tonkinson, 1985). It is thus not absurd to imagine niVanuatu people or communities using internal migration as a means of coping with climatic stressors (Kelman, 2008; Warrick, 2011, p. 340).

However, the fact that migration and mobility is a common practice in the Pacific (McAdam, 2012; Barnett \& Campbell, 2015; Lazrus, 2012; Warrick, 2011) does not negate the difficulties that may accompany permanent relocation (Campbell, 2012; Campbell \& Warrick 2014; Farbotko \& Lazrus 2012). Campbell (2012, p. 63) argues: 
coexistence of mobility and stability in many Pacific places... invokes the paradoxical notion of both roots and routes as important aspects of Pacific island lives ... Many migrants, even long-term ones, still consider themselves to belong to their land, even if they are physically dislocated from it.

Thus, while Pacific Islanders' "sense of history is strongly connected to mobility" (Farbotko \& Lazrus, 2012, pp. 15-16), it is "the prospect of permanent loss of land and selfdetermination, particularly if there is no forthcoming remedy for these losses from those who caused the damage" that complicates the idea of leaving land in the Pacific. In the case of the Maat people, who relocated from Ambrym to Efate after a volcanic eruption, most intended to eventually return to Ambrym and considered themselves Ambrymese even 15 years after resettlement (Tonkinson, 1985). Maintaining a relationship with their old village was crucial: This "territorial bond" to the "connecting homeland" is characteristic of migration in Vanuatu (Bonnemaison, 1985, pp. 57-59). A community perspective on climate-related migration in Vanuatu must thus consider the complexity and loss that relocation from landparticularly permanent relocation-entails.

The interviews I performed in January 2016 with ni-Vanuatu policymakers and stakeholders recognized this complexity. One policymaker in the National Disaster Management Office (NDMO) recalled a specific example in which an attempted relocation in 2009-from the island of Gaua to the island of Vanua Lava — went poorly due to a lack of cultural agreement or dialogue between the host and relocated communities (Interviewee 15). In his eyes, considerations of the cultural links that communities have to their land are thus crucial to successful relocation. Such sentiments align well with similar scholarship in the Pacific regarding climate migration (Barnett \& O'Neill, 2012; Campbell, 2012; Donner, 2015; Lazrus, 2012; McNamara \& Des Combes, 2015; Monson \& Foukona, 2014). To minimize cultural frictions, maintain cultural ties, and center a ni-Vanuatu understanding of land in climate-related resettlement policy, the voices of ni-Vanuatu communities should be sought out and adhered to in this policymaking.

One NGO worker in Vanuatu suggested that communities would most prioritize the transference of their specific community services - a church, a school, or a clinic- to ensure a smoother relocation (Interviewee 1). Another suggested that communities should aim to move to similar environments: For instance, fishing communities should attempt to retain access to coasts so as to maintain their fishing tradition (Interviewee 18). These suggestions indicate an interest in maintaining social networks, institutions, and practices in the event of relocation - all of which ultimately facilitate and ease the process (McNamara \& Des Combes, 2015; Monson \& Foukona, 2014; Rakova et. al, 2009). Barnett and Webber (2012, p. 53) observe that in the context of climate-related migration, community consultations on policy will almost always minimize "social and political costs" of the move. The concrete, community-minded suggestions from ni-Vanuatu decision-makers on ways to maintain links to land even after relocation seem to confirm this and further highlight the merits of a community-informed approach to climate-related migration.

A more obvious trend in my interviews was that communities may express preferences to move to a certain place over another. These preferences should be respected and attended to well before haphazard policy suggestions of, for example, relocating ni-Vanuatu people to a country like Australia. Interviewees demonstrated an overwhelming preference for internal migration. All 19 agreed that the ni-Vanuatu population would find internal migration not only more practical than cross-border migration, but also preferable from the standpoint of maintaining culture and way of life (Interviewees 1-19). For example, during Cyclone Pam in March 2015, the island of Mataso saw the internal (but temporary) relocation of certain communities, executed by the IOM. However, according to the director of an international 
NGO, a lack of consultation with the community ultimately resulted in a less-thanharmonious outcome:

[The move] was done by IOM, and they paid for everything. What this did is it created a huge lack of resilience, a huge expectation. If you moved normally, you would use your kinship networks. But here instead, the community felt very reliant, and very isolated. They felt like "we have nothing; we need everything." [...] It just ruined cultural ties. There's a way probably to do it that strengthens traditional systems of exchange, because traditional systems of exchange do happen all the time [...] Using the social networks makes the move more sustainable (Interviewee 1).

The lack of community consultation by the IOM during this temporary relocation denied the community a chance to express preferences for movement along certain social networks or kinship networks. This, in turn, led to a community that was significantly less well-integrated into its host community and that risked maladaptation. A policymaker in the Department of Energy, whose ancestral village in Ambrym had been relocated, reflected that communities would be best served if they could choose where to move, following existing social ties: "The ni-Vanuatu is a family-oriented people, and you have extended families in other islands [...] These connections help a lot, you have a second option [for relocation] this way" (Interviewee 4). Literature about climate-related relocations affirms these interviewees' preference for using kinship links to ease the prospect of migration. Monson and Foukona (2014) discuss the utility of established "social relations, and shared histories of intermarriage and exchange" in navigating resettlement in the Solomon Islands-Vanuatu's northern, Melanesian neighbor. In the context of Tuvalu, Mortreux and Barnett (2009) similarly assert that "the existence of social networks at the destination [...] provide[s] important practical support in terms of accommodation and employment connections, as well as providing a sense of community" (p. 107). Once again, it becomes evident that when a community must relocate, a community-based approach to relocation policy, developed by listening to the voices of the community in question, will not only be respectful and aligned with community preference. It will also lead to more meaningful policy.

The significance of the suggestions highlighted above is that they derive from culturally appropriate and relevant interests, which would inevitably arise through a communityinformed approach to climate-related migration. In an interview, the head of an umbrella organization of Vanuatu's civil society organizations expressed concern over the "diverse cultural dynamics" (Interviewee 3) that would be at stake when communities faced relocation due to climate change. However, he reflected, the national government and international aid organizations often do not seem to consider these cultural sensitivities when crafting climate change policy, which in turn leads to feelings of disconnection in local communities. Comments like this, highlighting a lack of consultation with local entities regarding climate change decision-making, were common throughout my fieldwork; $75 \%$ percent of interviewees advocated consultation and inclusion of smaller administrative units than the state in climate policy-whether these be the province, the area council, the tribal council, or another village-level decision-making body (Interviewees 1, 2, 3, 4, 5, 6, 8, 10, 11, 12, 13, 14). The decision-makers I spoke to thus seemed to advocate for the rights of communities to participate at all levels of climate change policymaking. Successful relocations that do occur will likely address community priorities: reliance on pre-existing networks and cultural ties, and the maintenance of livelihood and cultural tradition from place to place. Community members and local groups are much better acquainted with these than the national government or aid organizations. To not consult them despite this trove of knowledge- or to consult with them only late the process of climate policy formulationwould be foolish at best and irresponsible at worst. 


\section{Nikita Perumal}

It is also notable that many of these recommendations evoke similar approaches to those of a community-led relocation project in Papua New Guinea, another Melanesian country. Ursula Rakova, founder of the Tulele Peisa project to relocate 1,700 residents from the eroding Carteret Islands, writes: "We wish to maintain our cultural identity and live sustainably wherever we are. We are cognisant of the many complexities involved in integrating the Carterets' people into existing communities that are geographically, culturally, politically and socially different" (Rakova et al., 2009). As such, the project involves plans for exchange programs from host communities and migrant communities "for establishing relationships and understanding;" for the carryover of income-generating activities and social services like education and health programs; and for mechanisms to maintain "the links between the relocated Carterets' people and their home island, sea resources and any remaining clan members (who are not yet relocated)" (Rakova et al., 2009). The fact that the policy recommendations of the 19 interviewed stakeholders in Port Vila so closely resemble the carefully laid-out plans of Tulele Peisa suggests that community participation in decisionmaking makes for consistently strong, thoughtful, and locally appropriate policy. Records of climate-linked relocations in Fiji and the Solomon Islands have also revealed a similar community preoccupation with maintaining a source of livelihood, incorporating community participation in relocation activities, and retaining social institutions during relocation (McNamara \& Des Combes, 2015; Monson \& Foukona, 2014).

However, community input in discussions of climate migration might not advocate migration at all. Some communities will not be willing to leave their homes until there is no other option - which is certainly understandable given the widespread cultural ties to land outlined above. In the eyes of two ni-Vanuatu climate activists, to give up before they absolutely must is to give up on their claims to their home and to their culture (Interviewees $1 \& 5)$. Similarly, the assortment of policymakers and NGO workers interviewedstakeholders who are intimately familiar with climate change and the impacts it will have on Vanuatu-was largely in agreement that it was in the best interest of vulnerable communities to only move if alternative measures of in-situ adaptation had failed (Interviewees 1, 2, 3, 4, $5,6,8,9,10,11,13,15,18)$.

This preference aligns well with Allgood and McNamara's (2016, p. 380) recent findings that many of the I-Kiribati interviewed would consider migration as an optioninterestingly, at a higher rate than older fieldwork in Kiribati has shown-but specifically "an option of last resort." McNamara and Des Combes (2015), who examine a resettlement of a village in Fiji as a 'last resort' measure to sustain livelihoods, and Donner (2015), who draws lessons from the historical resettlement of the Gilbertese people to the Solomon Islands, also corroborate the preferences that Pacific Islanders have had for moving only if other adaptation options are no longer available. When this is the case-when community participation indicates a determined community will to first examine alternative options to migrationsuch decisions must be respected (Constable, 2016). And knowledge of these perspectives before climate migration policy is formed may help reorient this policy to more strongly emphasize preventive measures through in-situ adaptation.

The reluctance of ni-Vanuatu people to strongly consider migration makes Vanuatu's current governmental policies prioritizing climate resiliency projects- projects that build "the capacity of a community, business, or natural environment to prevent, withstand, respond to, and recover from" climate change (U.S. Climate Resilience Toolkit, 2016)-all the more logical. The interviews I conducted with NAB and civil society members reflected an overwhelming prioritization of adaptation projects that increase resilience within all sectors in Vanuatu, from agriculture and livestock to local affairs management. One NGO director explained the importance of these adaptation projects within the context of migration: 
From what I can tell from displacement, at least at the community level, we don't have the very, very low-lying atolls that we often talk about when people move. But the things people would be moving from would be the contamination of ground water, food security, etc.

On the island of Pele, for instance, 11 of the existing 23 groundwater wells had been affected by salinization within the past 25 years as a result of climate impacts (Interviewee 1). Because of this, the director reflected, there is a need for a stronger focus on adaptation projects that could build water security and pre-empt a move. Adaptation might also entail cultivating alternative livelihoods in islands where a key industry - such as the fishing of a particular aquatic species-is threatened by climate change (Interviewees 10 \& 11). This would allow the communities to remain, and "not necessarily mov[e] because one aspect of your livelihood has been altered" (Interviewee 1). Similarly, a technical advisor to NAB noted that the government needs to work towards "disaster proof" communities and climateresilient infrastructure (Interviewee 9), while a policymaker in the Department of Energy highlighted community resiliency as important because "it is not about curing, but also about prevention" (Interviewee 13). These community responses favoring adaptation should not be considered in a vacuum; rather, these adaptation strategies can contribute to effective policy on climate migration, in that they help minimize and pre-empt the conditions that would eventually culminate in climate-related relocation.

Interviewees' preference for in-situ adaptation strategies becomes even more relevant given the myriad of existing scholarship pointing to the resilience of traditional societiesand more specifically, of Pacific Islander communities - to natural disasters and environmental change (Barnett \& Campbell, 2015; Campbell, 2006; De Souza et al., 2015; Kelman \& West, 2009; McNamara \& Prasad, 2014; Nurse et al., 2014; Vachette, 2016). Many Pacific climate migration policy recommendations that exclude local context can be criticized as "not entirely recogniz[ing] the capacity of islands and local communities to adapt in situ" (De Souza et al., 2015 , p. 5). Kelman and West $(2009$, p. 2) point to the fact that "some characteristics" of SIDS - specifically their "tight kinship networks, unique heritage, a strong sense of identify and community, creativity for sustainable livelihoods, remittances from islander diasporas supporting life on SIDS, and local knowledge and experience of dealing with environmental and social changes throughout history"-may lend island communities substantive adaptive capacity to climate change and associated impacts. Regarding Vanuatu specifically, Vachette (2016, p. 30) notes that "ni-Vanuatu [...] have always showed a certain level of resilience to the uncertainty and severity of hazards through demonstration of preparedness, response and adaptation capacities," citing a host of literature about historical and cultural examples of niVanuatu resilience.

Furthermore, the findings of Farbotko and Lazrus (2012) and McNamara and Gibson (2009) — that Tuvaluans regard climate change mitigation and loss and damage compensation as needed responses to pre-empt climate-related migration-were mirrored in my interviews of ni-Vanuatu citizens and policymakers. When asked what 'responsibility' the international community had to respond to climate change and its associated impacts (including migration), many interviewees indicated that technical and financial transfers, under the category of a loss and damage mechanism, would be necessary (Interviewees 3, 4, 6, 8, 9, 10, 11, 12, 13, 14, 15). Moreover, the majority of interviewees believed that migration as a result of climate change was simply not yet an option that many ni-Vanuatu would consider (Interviewees 1, $2,4,5,6,7,10,11,12,13,15)$. With these perspectives in mind, it is difficult to understand the urgency of, for example, Wyett's (2014) suggestion that we begin to identify potential host countries for the expected climate migrants from Vanuatu and other countries.

An alternative to migration as a climate adaptation strategy is prevention in the form of significant investment by government and donors into adaptation projects, and in the form of 


\section{Nikita Perumal}

significant commitment by high-polluting countries to ensure mitigation and mechanisms for loss and damage. In eyes of the people I interviewed, international organizations, donors, and states need to address "the real roots [of the] problem" (Interviewee 15)-greenhouse gas emissions by more affluent countries - and to provide adaptation assistance through expertise and funds; only in doing so can they properly 'address' climate-related migration. This emphasis on lessening climate change is perhaps why many ni-Vanuatu assert that the correct response to the possibility of migration - and the one most strictly adhered to by its Ministry of Climate Change - is to continue to adapt to, and to fight against, climate impacts until relocation is necessary. In essence, community-informed international climate migration policy must, in addition to advocating community control over relocation, include efforts to prevent the circumstances that would precipitate climate-related migration. In the words of Mortreux and Barnett (2009, p. 111) "this is not to say that people should not have the choice to migrate, but rather that people should not be left with no choice but to migrate."

The summaries of the interviews I performed in Port Vila reveal a complex relationship with the prospect of climate-related migration in Vanuatu. These perspectives are indispensable to the formulation of policy around this issue, and understanding them slightly underwhelms the relevance of policy briefs and analyses that postulate in detail over the legality of a 'climate refugee' label or over possible host states for relocated Pacific Islanders. The people of Vanuatu, and possibly of other 'high' Pacific Islands, will likely not be contemplating migration across borders as a response to climate change (although contemplation of migration for other reasons, such as economic drivers and participation in seasonal worker programs, may be another story). Furthermore, policy that does approach migration policy in Vanuatu should spend substantial time discussing the preferences outlined here- - for internal migration based on kinship networks as a last resort, for increased mitigation and adaptation measures, for loss and damage mechanisms that rectify the harm already done, and for deep thoughtfulness in maintaining cultural ties, livelihoods, and social infrastructure.

These broader recommendations aside, this study mostly did not explore technical details that could contribute to community-informed migration policy, and this would be a fruitful place for future study. However, two technical recommendations from existing scholarship merit mention. First, "without approval and support of the local level, the implementation of national decisions will fail" (Betzold, 2015, p. 485). Any policy discussed or formulated on climate migration should thus establish clear procedures to ensure a participatory process of community-led, informed decision-making in said policy. Second, certain complexities arise with the idea of 'community', which throughout this paper has been discussed as largely monolithic. Not addressing these complexities could result in friction and the marginalization of certain community members' voices (Buggy \& McNamara, 2015). Given that migration is a highly individual decision, climate migration policy approaches should adhere to the four guidelines outlined by Buggy and McNamara (2015), in order to minimize the risk of maladaptation and of certain community members being denied an adequate say in relevant decisions.

\section{Conclusion}

The dominant narrative around Pacific Island 'climate refugees' and the associated policy analyses and recommendations that accompany it are often grossly at odds with the perspectives and intentions of the climate-vulnerable island communities themselves. As Allgood and McNamara (2016, p. 271) note, "documenting and understanding local perspectives of climate change experiences, adaptation and migration is often overlooked in these discussions [about climate-related migration] despite being crucial to them." This paper thus attempted to fill this gap, by examining ni-Vanuatu perspectives on the possibility of climate-related migration in the country. In Vanuatu, community-informed policy responses 
to climate migration would allow for community control over movement and would place a strong emphasis on maintaining cultural and livelihood links to land in the event of relocation. Policy that takes into account the wishes of the ni-Vanuatu population would also emphasize prevention and minimization of the circumstances that precipitate climate migration. Mitigation of loss and damage would thus be crucial facets of an inclusive approach to climate migration.

The results of the fieldwork elaborated here add to the body of anthropological literature contesting the traditional 'climate refugee' narrative from the perspective of a less sensationalized Pacific Island country that is nonetheless often swept up in mainstream climate change migration policy and media coverage. Given the visible lack of scholarship on approaches to climate change-related migration in Vanuatu and in other, less mediatized island states, much more work should be done to broaden this base of scholarship. As mentioned above, it would be helpful for this study to be replicated in a way that better draws from directly impacted community members, rather than policymakers and NGO practitioners based in the capital alone. It would also be interesting, in future research, to conduct interviews with a greater sample of non-ni-Vanuatu people, and with a greater sample of people with less familiarity with the country (for instance, adaptation consultants and multilateral development bank representatives) to allow for comparison.

This paper also contributes to the literature in that it attempts to close the gap between technical, policy-oriented papers (which may often be out of touch with community needs) and anthropologies of communities that describe, but rarely prescribe. While this is one small attempt to bridge this gap, there is an urgent need to further connect the divided disciplines of environmental anthropology and environmental policy on all climate-related issues, including climate-related migration. Both disciplines have valuable potential to contribute to the other. To study climate vulnerable communities without applying empirical findings to climate policy approaches - or worse, to create policy on climate-related migration without a thorough understanding of the interests or expectations of local communities-would be a lamentable waste of academic resources.

One of the first interviews I conducted in Port Vila was with a passionate ni-Vanuatu climate activist, whose quotes I have used throughout this paper. When I asked him about how he feels about the idea of migrating due to climate change, he responded in the following, halting manner:

That issue, I mean, for me, personally, talking about migration because of climate $[\ldots]$ that is something that is really, really, well for me it's really hard for me to $[\ldots]$ For me, personally, I would say that I'm not going to move if there's a climate change event or impacts in my home. Because, you know, the place where I live is where I belong (Interviewee 2).

These words, and the hesitation behind them, perfectly encapsulate what it means to contemplate change-related migration in a small island state like Vanuatu. They also embody the sort of richness and complexity that can only be achieved by truly engaging with the expressed interests and concerns of the communities that face relocation. Without a fundamental understanding of this complexity, policy discussions for addressing climaterelated migration are bound to be locally inappropriate and uninformed. Listening to perspectives in Vanuatu around the prospect of climate-related migration reveals communities that are reluctant to move, that regard losses to livelihood and culture with trepidation, and that are actively dedicated to empowerment and resilience. It also serves as a strong reminder that seeking out and centering the voices of these communities is a crucial component of creating sensible, effective policy relating to climate change. 


\section{Acknowledgements}

I would like to extend a heartfelt thank you to the various professors and faculty members at Columbia University who helped me in designing, funding, and carrying out this research project. I am also grateful to the Columbia Global Policy Institute, whose Undergraduate Global Policy Fellowship allowed for me to travel to Port Vila for my fieldwork, and to the editors of Island Studies Journal for consulting with me on my manuscript. Lastly, I want to sincerely thank the various scholars, policymakers, activists, and civil society members of Vanuatu who were generous enough to share their time with me, as well as my incredibly helpful and kind contacts at the NAB Secretariat the University of the South Pacific-Emalus campus.

\section{References}

Allgood, L., \& McNamara, K. (2017). Climate-induced migration: exploring perspectives in Kiribati. Singapore Journal of Tropical Geography, 38(2017), 370-385. https://doi.org/10.1111/sjtg.12202

Ash, J., \& Campbell, J. (2016). Climate change and migration: the case the Pacific Islands and Australia. The Journal of Pacific Studies, 36(1), 53-72.

Barnett, J. (2017). The dilemmas of normalising losses from climate change: towards hope for Pacific atoll countries. Asia Pacific Viewpoint, (58)1, 3-13. https://doi.org/10.1111/apv.12153

Barnett, J., \& Webber, M. (2012). Migration as adaptation. In J. McAdam (Ed.) Climate change and displacement: multidisciplinary perspectives (pp. 37-56). Portland \& Oxford: Hart.

Barnett, J., \& Campbell, J. (2015). Climate change and small island states: power, knowledge and the South Pacific. New York: Routledge.

Barnett, J., \& O’Neill, S. (2012). Islands, resettlement and adaptation. Nature Climate Change, 2(1), 8-10. https://doi.org/10.1038/nclimate1334

Bedford, R. (1973). New Hebridean mobility: a study of circular migration. Canberra: Australian National University.

Bedford, R., \& Campbell, J. (2013). Migration and climate change in Oceania. In E. Piguet \& F. Laczko (Eds) People on the move in a changing climate (pp. 177 - 204). Dordrecht: Springer.

Betzold, C. (2015). Adapting to climate change in small island developing states. Climate Change, 133, 481-489. https://doi.org/10.1007/s10584-015-1408-0

Biermann, F., \& Boas, I. (2008). Protecting climate refugees: the case for a global protocol. Environment: Science and Policy for Sustainable Development, 50(6), 8-17.

Bonnemaison, J. (1985). The tree and the canoe: roots and mobility in Vanuatu societies. Pacific Viewpoint, 25(2) 117-151.

Buggy, L., \& McNamara, K. (2015). The need to reinterpret 'community' for climate change adaptation: a case study of Pele Island, Vanuatu. Climate and Development, 8(3), 270280. https://doi.org/10.1080/17565529.2015.1041445

Byravan, S., \& Rajan, S (2006). Sea level rise and climate change exiles: a possible solution. Climate Policy, 6, 247-252. https://doi.org/10.1080/14693062.2006.9685599

Campbell, J. (1990). Disasters and development in historical context: tropical cyclone response in the Banks Islands, Northern Vanuatu. International Journal of Mass Emergencies and Disasters, 8(3), 401-424.

Campbell, J. (2006). Traditional disaster reduction in Pacific Island communities. GNS Science Report 2006/38.

Campbell, J. (2012). Climate-induced community relocation in the Pacific: the meaning and importance of land. In J. McAdam (Ed.) Climate change and displacement: multidisciplinary perspectives (pp. 57-80). Portland \& Oxford: Hart. 
Campbell, J., \& Warrick, O. (2014). Climate change and migration issues in the Pacific. Fiji: United Nations Economic and Social Commission for Asian and the Pacific / International Labour Organization.

Central Intelligence Agency (2014). Australia-Oceania: Vanuatu. Retrieved from https://www.cia.gov/library/publications/the-worldfactbook/geos/print/country/countrypdf nh.pdf.

Comes, M., Dubbert, M., Garschagen, M., Hagenlocher, M., Sabelfeld., Yew Jin Lee, U., Grunewald, L., Lanzendörfer, M., Mucke, P., Neuschäfer, O., Pott, S., Post, J. Schramm, S.,Schumann-Bölsche, D., Vandemeulebroecke, B., Well, T., \& Birkmann, J. (2016). World Risk Report. Berlin \& Bonn: Bündnis Entwicklung Hilft / ited Nations University - EHS.

Constable, A. (2016). Climate change and migration in the Pacific: options for Tuvalu and the Marshall Islands. Regional Environmental Change, 17(2017), 1029-1038

Craven, L. (2015). Migration-affected change and vulnerability in rural Vanuatu. Asia Pacific Viewpoint, 56(2), 223-236. https://doi.org/10.1111/apv.12066

De Souza, R.M., Henly-Shepard, S., McNamara, K., \& Fernando, N. (2015). Re-framing island nations as champions of resilience in the face of climate change and disaster risk. UNU-EHS working paper series, 17. Bonn: United Nations University Institute of Environment and Human Security.

Docherty, B., \& Giannini, T. (2009). Confronting a rising tide: a proposal for a convention on climate change refugees. Harvard Environmental Law Review, 33(2), 349-403.

Doherty, B. (2015). Labor champions plan to resettle Pacific climate change migrants. The Guardian, $10 \quad$ November. https://www.theguardian.com/environment/2015/nov/11/labor-champions-planto-resettle-pacific-climate-change-migrants.

Donner, S. (2015). The legacy of migration in response to climate stress: learning from the Gilbertese resettlement in the Solomon Islands. Natural Resources Forum, 39, 191-201.

Falstrom, D. (2001). Stemming the flow of environmental displacement: creating a convention to protect persons and preserve the environment. Colorado Journal of International Environmental Law and Policy, 2, 1-19.

Farbotko, C., \& Lazrus, H. (2012). The first climate refugees? Contesting global narratives of climate change in Tuvalu. Global Environmental Change, 22(2), 382-90. https://doi.org/10.1016/j.gloenvcha.2011.11.014

Gerrard, M.B., \& Wannier, G.E. (2013). Threatened island nations: legal implications of rising seas and a changing climate. New York: Cambridge University Press.

Granderson, A. (2017). Value conflicts and the politics of risk: challenges in assessing climate change impacts and risk priorities in rural Vanuatu. Climate and Development, 1-14. https://doi.org/10.1080/17565529.2017.1318743

Hodgkinson, D., \& Young, L. (2013). In the face of looming catastrophe. In M.B. Gerrard \& G.E. Wannier (Eds.) Threatened island nations: legal implications of rising seas and a changing climate (pp. 299-336). New York: Cambridge University Press.

Hugo, G.J., \& Bedford, R.D. (2012). Population movement in the Pacific: a perspective on future prospects. Wellington: Department of Labor.

Human Rights and Equal Opportunity Commission (HREOC) (2008). Human rights and climate change background paper. Australian Human Rights Commission. https://www.humanrights.gov.au/papers-human-rights-and-climate-changebackground-paper.

Interviewee 1 (Employee at GIZ), interviewed by Nikita Perumal, Port Vila, Shefa Province, Vanuatu, January 2016.

Interviewee 10 (Local NGO worker), interviewed by Nikita Perumal, Port Vila, Shefa Province, Vanuatu, January 2016. 
Interviewee 11 (Local NGO worker), interviewed by Nikita Perumal, Port Vila, Shefa Province, Vanuatu, January 2016.

Interviewee 12 (Policymaker in Department of Livestock), interviewed by Nikita Perumal, Port Vila, Shefa Province, Vanuatu, January 2016.

Interviewee 13 (Policymaker in Department of Local Authorities), interviewed by Nikita Perumal, Port Vila, Shefa Province, Vanuatu, January 2016.

Interviewee 14 (Policymaker in Department of Foreign Affaairs), interviewed by Nikita Perumal, Port Vila, Shefa Province, Vanuatu, January 2016.

Interviewee 15 (Policymaker in Vanuatu National Disaster Management Office), interviewed by Nikita Perumal, Port Vila, Shefa Province, Vanuatu, January 2016.

Interviewee 16 (Student and climate activist), interviewed by Nikita Perumal, Port Vila, Shefa Province, Vanuatu, January 2016.

Interviewee 17 (climate activist), interviewed by Nikita Perumal, Port Vila, Shefa Province, Vanuatu, January 2016.

Interviewee 18 (Scholar and employee at Vanuatu Cultural Centre), interviewed by Nikita Perumal, Port Vila, Shefa Province, Vanuatu, January 2016.

Interviewee 19 (International Organization for Migration representative), interviewed by Nikita Perumal, Port Vila, Shefa Province, Vanuatu, January 2016.

Interviewee 2 (International NGO worker and climate activist), interviewed by Nikita Perumal, Port Vila, Shefa Province, Vanuatu, January 2016.

Interviewee 3 (Representative of multi-organization civil society coalition), interviewed by Nikita Perumal, Port Vila, Shefa Province, Vanuatu, January 2016.

Interviewee 4 (Policymaker in Department of Energy), interviewed by Nikita Perumal, Port Vila, Shefa Province, Vanuatu, January 2016.

Interviewee 5 (International NGO worker), interviewed by Nikita Perumal, Port Vila, Shefa Province, Vanuatu, January 2016.

Interviewee 6 (Policymaker in Provincial Offices), interviewed by Nikita Perumal, Port Vila, Shefa Province, Vanuatu, January 2016.

Interviewee 7 (Professor at University of the South Pacific - Emalus Campus School of Law), interviewed by Nikita Perumal, Port Vila, Shefa Province, Vanuatu, January 2016.

Interviewee 8 (Policymaker in Department of Energy), interviewed by Nikita Perumal, Port Vila, Shefa Province, Vanuatu, January 2016.

Interviewee 9 (NAB Technical Advisor), interviewed by Nikita Perumal, Port Vila, Shefa Province, Vanuatu, January 2016.

Kelman, I. (2008). Island evacuation. Forced Migration Review, 31, 20-21.

Kelman, I. (2010). Hearing local voices from small island developing states for climate change. Local Environment, 15(7), 605-619. https://doi.org/10.1080/13549839.2010.498812

Kelman, I., \& West, J. (2009). Climate change and small island developing states: a critical review. Ecological and Environmental Anthropology. 5(1), 1-16.

Lazrus, H. (2012). Sea change: island communities and climate change. Annual Review of Anthropology, 41(1), 285-301. https://doi.org/10.1146/annurev-anthro-092611$\underline{145730}$

McAdam, J. (2012). Climate change, forced migration, and international law. Oxford: Oxford University Press. https://doi.org/10.1093/acprof:oso/9780199587087.001.0001

McAdam, J., \& Loughry, M. (2009). We aren't refugees. Inside Story, 30 June. http://insidestory.org.au/we-arent-refugees.

McNamara, K.E., \& Gibson, C. (2009). 'We do not want to leave our land': Pacific ambassadors at the United Nations resist the category of 'climate refugees'. Geoforum, 40(3), 475-483. https://doi.org/10.1016/j.geoforum.2009.03.006

McNamara, K.E., \& Des Combes, H.J. (2015). Planning for community relocations due to climate change in Fiji. International Journal of Disaster Risk Science, 6(3), 315-319. 
McNamara, K.E., \& Prasad, S.S. (2014). Coping with extreme weather: communities in Fiji and Vanuatu share their experiences and knowledge. Climatic Change, 123(2), 121-132. https://doi.org/10.1007/s10584-013-1047-2

Monson, R., \& Foukona, J. (2014). Climate-related displacement and options for resettlement in Solomon Islands. In S. Leckie (Ed.) Land solutions for climate displacement (pp. 291-316). New York: Routledge.

Mortreux, C., \& Barnett, J. (2009) Climate change, migration and adaptation in Funafuti, Tuvalu. Global Environmental Change, 19(1), 105-12. https://doi.org/10.1111/1477$\underline{8947.12082}$

NAB (2016). NAB Portal. National Advisory Board on Climate Change and Disaster Risk Reduction. http://www.nab.vu/.

National Oceanic and Atmospheric Administration (2016). U.S. climate resilience toolkit. National Oceanic and Atmospheric Administration, 1 March. https://toolkit.climate.gov/get-started/overview.

Nurse, L., McLean, R., Agard, J., Briguglio, L., Duvat-Magnan, V., Pelesikoti, N., Tompkins, E., Webb, A., Campbell, J., Chadee, D., Maharaj, S., Morin, V., Oldenborgh, G., Payet, R., \& Scott, D. (2014). Small islands. In V.R. Barros et al. (Eds.) Climate change 2014: impacts, adaptation, and vulnerability. Part B: regional aspects. contribution of Working Group II to the fifth assessment report of the Intergovernmental Panel on Climate Change (pp. 1613-1654). Cambridge, UK \& New York: Cambridge University Press.

Petrou, K. (2017). Before, it wasn't like this...: longitudinal research and a generation of continuity and change in rural-urban migration in Vanuatu. Asian and Pacific Migration Journal, 26(1), 31-55. https://doi.org/10.1177/0117196816683405

Petz, D. (2013). Neglected displacement: human mobility in pacific disaster risk management and climate change adaptation mechanisms. Geneva: Norwegian Refugee Council/International Displacement Monitoring Centre.

Rakova, U., Patron, L., \& Williams, C. (2009). How-to guide for environmental refugees. Our World, 16 June. https://ourworld.unu.edu/en/how-to-guide-for-environmentalrefugees.

Scott, J. (1998). Seeing like a state: how certain schemes to improve the human condition have failed. New Haven: Yale University Press.

Siméoni, P., \& Ballu, V. (2012). Le mythe des premiers réfugiés climatiques : mouvements de populations et changements environnementaux aux îles Torrès (Vanouatou, Mélanésie). Annales de géographie, 685,(3), 219-241. https://doi.org/10.3917/ag.685.0219

Solomon, M., \& Warner, K. (2013). Protection of persons displaced as a result of climate change: existing tools and emerging frameworks. In M.B. Gerrard \& G.E. Wannier (Eds.) Threatened island nations: legal implications of rising seas and a changing climate (pp. 243-298). New York: Cambridge University Press.

Tonkinson, R. (1985). Forever Ambrymese? Identity in a relocated community, Vanuatu. Pacific Viewpoint, 26(1), 139-159.

UNDP (2014). Risk governance assessment report: strengthening climate and disaster risk governance in Vanuatu. Port Vila: Government of Vanuatu.

United Nations High Commissioner for Refugees (UNHCR) (1951). Convention and protocol eelating to the status of refugees. UNHCR. http://www.unhcr.org/3b66c2aa10.html.

Vachette, A. (2016). Networked disaster governance in Vanuatu: the anatomy of an inclusive and integrated system to build resilience in a small island developing state. Doctoral dissertation, James Cook University. 
Warrick, O.C. (2011). Local voices, local choices? vulnerability to climate change and communitybased adaptation in rural Vanuatu. Doctoral dissertation, University of Waikato.

Webb, J., Vorbach, D. Boydell, E., Mcnaught, R., \& Sterrett, C. (2015). Tools for CBA: lessons from NGO collaboration in Vanuatu. Coastal Management, 43(4), 407-423. https://doi.org/10.1080/08920753.2015.1046807

Williams, A. (2008). Turning the Tide: Recognizing Climate Change Refugees in International Law. Law \& Policy, 30(4), 502-529. https://doi.org/10.1111/j.14679930.2008.00290.x

World Bank (2016). Vanuatu. World Bank DataBank - World Development Indicators. http://databank.worldbank.org $/$ data/reports.aspx?source $=2 \&$ country $=V U T$

Wyett, K. (2014). Escaping a rising tide: sea level rise and migration in Kiribati. Asia and the Pacific Policy Studies, 1, 171-185. https://doi.org/10.1002/app5.7

Zetter, R. (2010). The meaning and importance of land. In J. McAdam (Ed.) Climate change and displacement: multidisciplinary perspectives (pp. 131-150). Portland \& Oxford: Hart. 